\title{
High Temperature Laser Scanning Confocal Microscopy for real-time studies of phase transformations.
}

\author{
Dominic J. Phelan*, Mark H. Reid* and Rian J. Dippenaar* \\ * Faculty of Engineering, University of Wollongong, Wollongong, NSW, 2500, Australia \\ Over the past 8 years extensive work has been undertaken utilising Laser Scanning Confocal \\ Microscopy (LSCM) to investigate high temperature phase transformations, primarily in iron based \\ alloys. A broad range of phenomenon has been studied including solidification, the peritectic \\ transformation and reaction, delta-ferrite to austenite phase transformation and austenite \\ decomposition. This presentation reviews the technique, specific experimental procedures developed \\ by the authors and a selection of our findings.
}

In-situ experimental observations of high temperature phase transformations in iron-carbon alloys, were made using laser-scanning confocal microscopy (LSCM). Samples are placed in a gold plated ellipsoid infrared heating furnace powered by a $1.5 \mathrm{~kW}$ halogen lamp, shown schematically in Figure 1, under a ultra-high purity inert atmosphere, $>99.9999 \%$ Ar. The temperature, measured by thermocouples incorporated in the crucible holder, is displayed on a monitor and simultaneously recorded with the image on videotape and/or DVD at a rate of 30 frames per second. Magnifications up to $1350 \mathrm{x}$ at a resolution of $0.25 \mu \mathrm{m}$ can be obtained using a He-Ne laser.

Observations typical of those generated using the LSCM facility are presented in Figures 2 and 3. Comparison of these figures taken from the upper and lower temperature range respectively clearly shows the capability of the technique to provide optically clear images despite high levels of thermal emission. Figure 2 follows the peritecitic transformations where austenite $(\gamma)$ grows into both the liquid phase (L) and the delta-ferrite phase $(\delta)$. In this example the austenite phase grows into the delta-ferrite phase with a dendritic like morphology. In the second series, a number of Widmanstätten ferrite plates is observed to grow into the austenite, having initiated from a grain boundary allotriomorph. These plates were subsequently overgrown by pearlite, providing an interesting microstructure for analysis using Electron Backscatter Diffraction (EBSD) to probe issues relating to the nucleation of the plates, as shown in Figure 4. In this instance the small misorientation between allotriomorph and Widmanstätten plates supports sympathetic nucleation as the mode of nucleation.

High Temperature Laser Scanning Confocal Microscopy provides an elegant tool for in-situ observations of phase transformations in materials. Kinetic data extracted form the real-time videos have provided important new information for the study of phase transformations in iron based alloys. Also, having an in-situ record of the exact microstructural development of samples has been advantageous in post transformation materials characterisation using EBSD, as well as Focussed Ion Beam milling and imaging (FIB). 

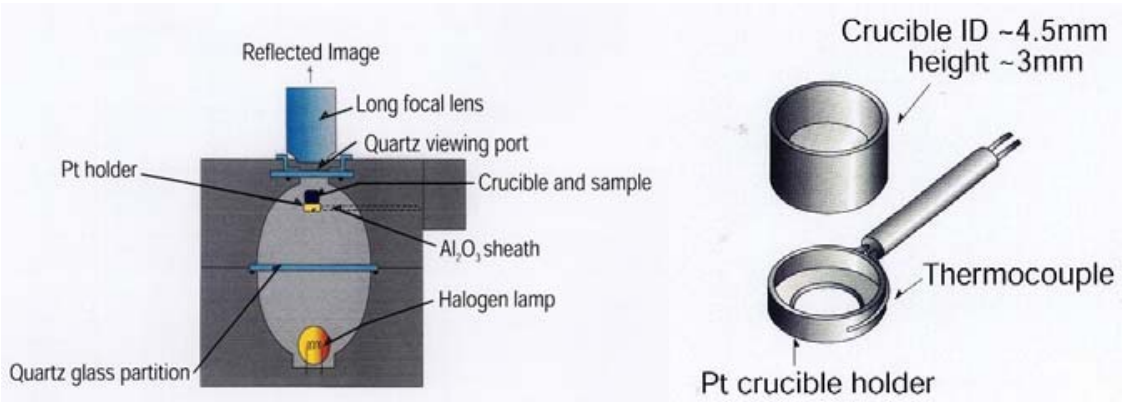

Figure 1 Schematic diagram of the LSCM furnace and sample holder.
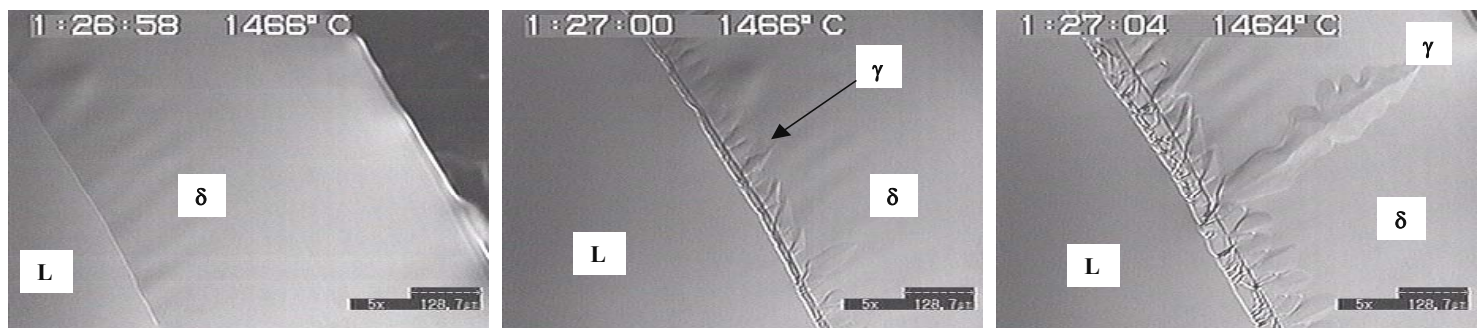

Figure 2 Peritectic Transformation with austenite growing into delta-ferrite with a dendritic like morphology.

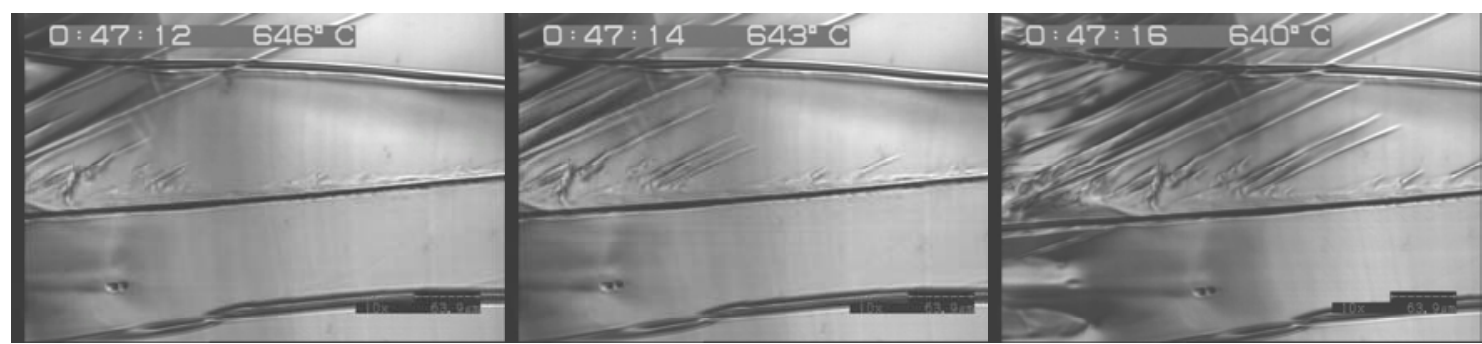

Figure 3. Austenite decomposition $\mathrm{Fe}-0.18 \mathrm{wt} \% \mathrm{C}$ alloy, with Widmanstätten plates growing from a grain boundary allotriomorph.
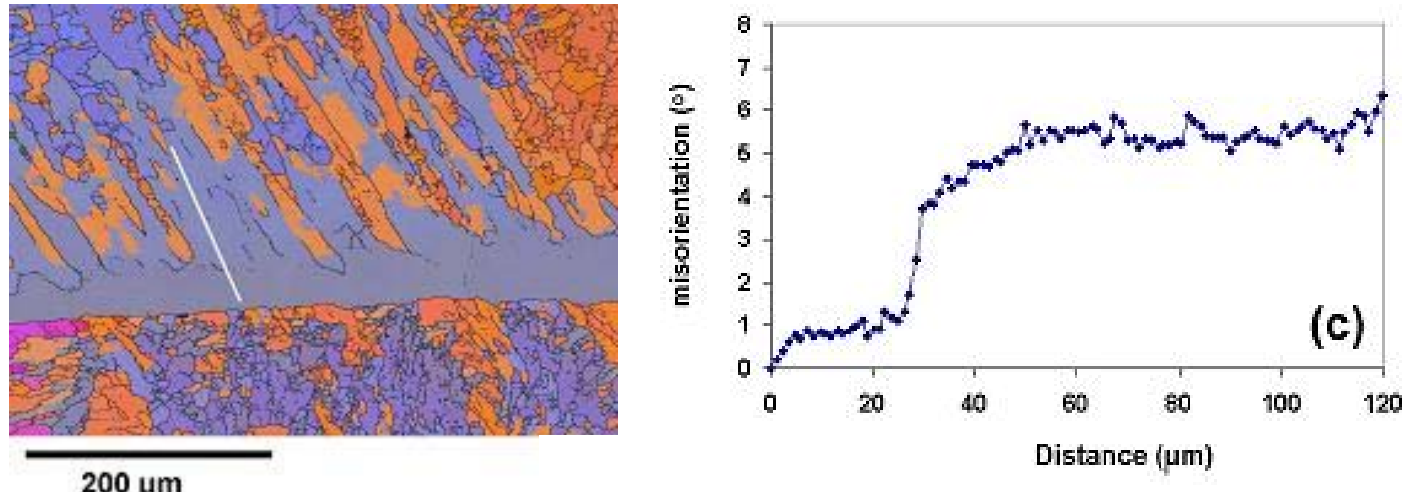

$200 \mu \mathrm{m}$

Figure 4 EBSD analysis of isolated Widmanstätten ferrite plates showing a 5 degree misorientation between allotriomorph and attendant plates 